in Early American Geography", and also in "The Heights of Mountains: An Historical Notice" (1958).

Altogether this collection, amply documented by 44 pages of references and notes, is one not to be neglected; it does more than remind the reader of one man's contributions over fifty active years: it gives many pointers for work still needed.

L. Dudley Stamp*

\section{SPECTROSCOPY AT WORK}

\section{Spectroscopic Analysis of Gas Mixtures}

By O. P. Bochkova and E. Ya. Shreyder. Edited by S. E. Frisch. Translation edited by Charles P. Poole, jun. Pp. $x i+313$. (New York: Academic Press, Inc.; London: Academic Press (London), Ltd., 1965.) $116 s$.

\section{Applied Infrared Spectroscopy}

Edited by David N. Kendall. Pp. xv +560 . (New York: Reinhold Publishing Corporation; London: Chapman and Hall, Ltd., 1966.) $\$ 23 ; 184 s$.

Spectroscopy enables us to discourse, albeit often with crossed swords, on topics as diverse as the origins of archaeological silver and chemical species in comet tails. There are, however, more mundane uses, some of which are discussed below.

Spectroscopic Analysis of Gas Mixtures is a workmanlike translation of the second Russian edition (1963). It does contain, though, some scientific obscurities, as on page 133, line $12, " \ldots$ a high electron temperature concentration. ..." There are also a few inconsistent transliterations from the Cyrillic script; indeed the author's name Shreyder is rendered differently on the cover and in the foreword.

The title is somewhat misleading, as the main theme concerns analysis, by visible emission spectroscopy, of mixtures which may contain noble gases, hydrogen or air constituents. Throughout, the treatment is largely empirical and it is stated that spectroscopic and spectroanalytical techniques have been deleted to save space. I feel that had the authors eliminated all the repetitions, condensed the numerous qualitative passages and omitted to state the obvious, they could profitably have reduced the size of the book still further.

The six chapters cover the nature and generation of discharges, equipment, methodological problems, typical analysis of mixtures, and absorption techniques. There are five short appendixes giving, respectively, details of sensitive spectral lines; analytical line pairs; Soviet spectrographs; Soviet photomultipliers, and finally some poorly reproduced spectrograms. Most of the circuit diagrams are unusable because inadequate details of components are given. A useful feature is the list of 502 references, nearly half being to Russian sources.

This book is unlikely to interest the general spectroscopist but could provide useful information to someone practising in the field.

In contrast, Applied Infrared Spectroscopy has twentyone contributors and covers many topics. There are five chapters on pharmaceuticals, polymers, essential oils, coal and public analyses. The remaining eleven chapters cover elementary, largely qualitative theory, instrumentation, sample preparation, interpretation of spectra, plant stream analyses, attenuated total reflectance, microtechniques, the use of computers and documentation. There is a small section on inorganic applications and about a page on kinetics.

The editor states that some overlapping of content is inevitable in maintaining contributors' styles. In my opinion "some overlapping" is an understatement. There is excessive, often tedious, overlapping which, with planning, could have been greatly reduced without detracting from an otherwise readable and informative book. Many important industrial aspects are covered, * Prof. Sir Dudley Stamp died on August 8, 1966. but these could have been extended, or the high cost of the book reduced, by combining or eliminating some of the contents. For example, Chapter 6, "Infrared on the Chemist's Bench", although excellent, contains littlo that is not mentioned elsewhere in the book. On the other hand, its correlation chart (page 210) is highly compressed and one would havo expected additionsl textual amplification.

On the credit side, there is an excellont section on interpretation, some useful information on microsampling. about 900 references and a good 24-page subject index. The book will doubtless prove a useful addition to the shelves of the wealthier libraries.

A. G. Brigas

\section{Representation Theory of Finite Groups}

By Martin Burrow. (Academic Paperbacks.) Pp. ix +185. (New York: Academic Press, Inc.; London: Academic Press, Inc. (London), Ltd., 1965.) $\$ 3.45 ; 27 s .3 d$.

THE most recent addition to the attractive series of Academic Paperbacks is a concise account of the Repre. sentation Theory of Finite Groups by Martin Burrow, a member of the Courant Institute of Mathematical Sciencos in New York. The book fills a real need for a modern, self-contained exposition of the subject, and fills it well. Of course, the reader cannot expect to find on a mere 180 pages the same amount of material as in the encyclopaedic volume Representation Theory of Finite Groups and Associative Algebras by C. W. Curtis and I. Reiner (Wiley, New York, 1962), treated in the same width and depth. But it is my plessant duty to record that the author succeeds in guiding the reader, who is supposed to be equipped only with a knowledge of linear algebra and that elusive commodity called "mathematical maturity", from the very beginnings right up to the intricacies of the recently created modular representation theory (but stopping short of Brauer's blocks of eharacters). The material is standard, culminating in such classies as Burnside's proof that the groups of order $p^{\alpha} q^{\beta}$ are soluble or the actual character tables of the icosahedral group, but the spirit behind the development is modern, extensive use being made of the representation module. Many wellchosen examples serve as illustrations and are treated in much detail, and each chapter ends with a collection of exereises. The book is equally suitable for self-study and as the basic text for a course of about first-year postgraduate level. It should be noted, however, that this book is concerned with pure representation theory, not with its many applications in quantum physics, crystallography, otc.

K. A. Hirsch

\section{Automatic Digital Calculators}

By A. D. Booth and Kathleen H. V. Booth. Third edition. Pp. xi 263 . (London: Butterworth and Co. (Publishers), Ltd., 1965.) 52s. 6d.

Frrst published in 1953, with a second edition in 1956, the third edition of this well established book appears after an interval of time during which there have been dramatic developments in computer technology', matched by a proliferation of applications in scientific, technological and commercial fields. As the authors point out, the bibliography in the second edition contained some sixty published texts and this is increased in the third edition to about three hundred. It is inevitable, therefore, that this book should contain a good deal that is now only of historical interest; nevertheless with the revisions incorporated in the present edition it is still useful and authoritative.

Apart from the very adequate historical account of the development of computers, the discussion on hardware is demanding on the general reader and a background of at least a first year undergraduate course in physics and mathematics is a prerequisite for its comprehension. Programming is introducod by discussing a simple basic 